\title{
Editorial
}

\section{Transgene containment by molecular means - is it possible and cost effective?}

\author{
Bao-Rong LU \\ Ministry of Education Key Laboratory for Biodiversity and Ecological Engineering, Institute of Biodiversity Science, Fudan University, \\ Shanghai, 200433, China. E-mail: brlu@fudan.edu.cn
}

\begin{abstract}
With the rapid advancement of transgenic biotechnology, large numbers of transgenic crops have been produced and released for commercial cultivation (James, 2001), raising considerable biosafety concerns all over the world. One of the major issues is the potential ecological risk resulting from transgenes escaping into and persisting in the environment. The extensive on-going debate on this issue (Arriola, 1997; Wolfenbarger and Phifer, 2000; Crawley et al., 2001; Prakash, 2001; Dale et al., 2002) poses challenging questions regarding the research directions that need to be taken to ensure that biotechnology outputs are responsibly deployed worldwide. Unless these biosafety issues are satisfactorily addressed, large-scale commercial release of the transgenic crops developed and further advancement of transgenic biotechnology are likely to be hampered. For an in-depth review of crop-to-wild gene flow, see Jenczewski et al. (2002) in this number of EBR. Here the more specific issue of the effectiveness of preventing gene flow from occurring will be discussed.
\end{abstract}

\section{GENE FLOW UNDER NATURAL CONDITIONS}

The escape of transgenes from GM crops usually occurs through gene flow, mainly by cross-pollination (outcrossing). As illustrated in Figure 1, gene flow is twodirectional under natural conditions. It has been found to occur not only between different varieties of the same species (crop-to-crop), but also between crop species and their weedy/wild relatives (crop-to-wild). Occasionally, gene flow has also been found between crop and less related wild species (Rieger et al., 2001).

Studies have shown that crop-to-crop and crop-towild gene flow is surprisingly widespread (Langevin et al., 1990; Arriola and Ellstrand, 1996; Snow, 2002; $\mathrm{Lu}$ et al., 2003). Gene flow from transgenic to non-transgenic rice varieties was as high as $0.53 \%$ under experimental conditions (Messeguer et al., 2001). Similar results are observed in many other crop species under experimental and natural conditions. The rate of crop-towild gene flow depends essentially on the genetic compatibility of crop species with their weedy/wild relative species. Compatibility between crops and their weedy populations is relatively high, because the weedy populations are usually derived from volunteers of the crop species, or from offspring of hybrids between crops and their wild relatives. Compatibility between crops and their wild relative species varies depending on their biosystematic relationships (Lu et al., 2000; 2003). In fact, the reproductive barriers between many crops and their direct progenitors and close relatives are often inadequate. Our unpublished data showed that the maximum gene flow from cultivated rice to its wild relative, Oryza rufipogon, could be as high as 3\%, and the distance of rice pollen flow could reach as far as $110 \mathrm{~m}$ in natural habitats. As shown in Figure 2, spontaneous hybridization between wild and cultivated rices growing in proximity generates many intermediate types.

\section{POSSIBLE CONSEQUENCES OF TRANSGENE ESCAPE FROM GENETICALLY MODIFIED CROPS}

Gene flow between crops and weedy/wild relatives seems inevitable, as the crop and the wild/weedy gene pools are not exclusive. Likewise, transgene escape through gene flow will occur from transgenic crops to their non-transgenic counterparts (crop-to-crop), or to their sexually compatible weedy/wild relatives (crop-towild) unavoidably (Ellstrand et al., 1999; Snow, 2002). If a GM crop has a sympatric distribution and synchronized flowering period, and is highly compatible, with its 


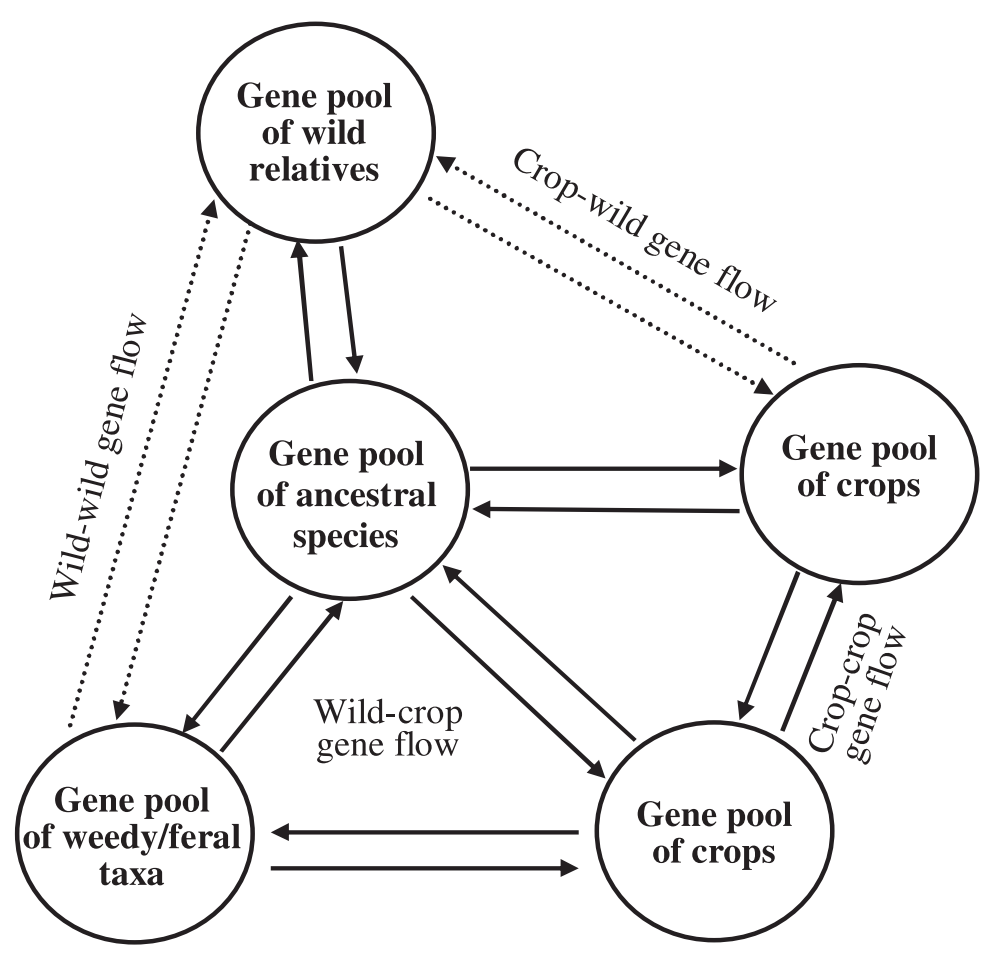

Figure 1. Reciprocal crop-to-crop and crop-to-wild gene flow is commonly found among plant species.

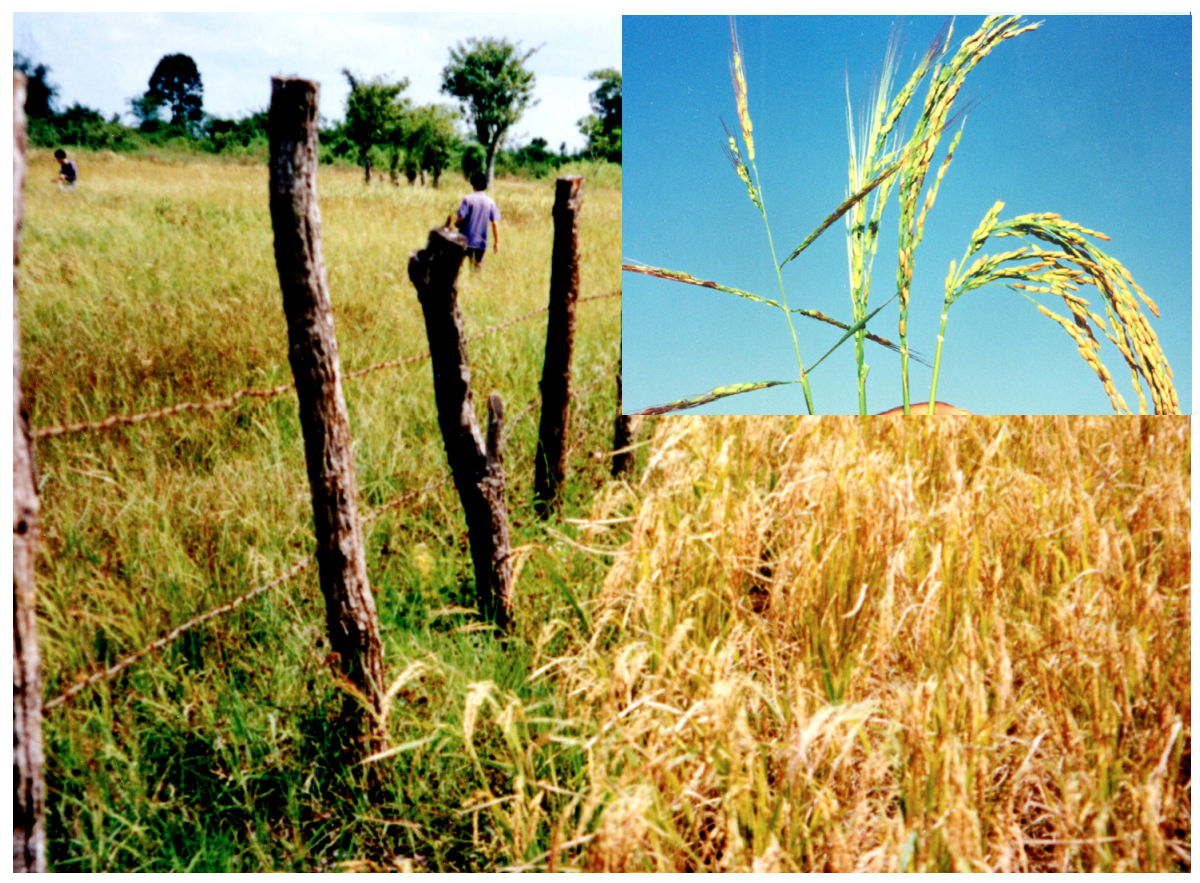

Figure 2. Hybrids and introgression types of rice are commonly found in the bordering area between cultivated (right) and wild (left) rice species. The picture on up-right corner shows the close-up of the perennial common wild rice (Oryza rufipogon, left), Asian cultivated rice (O. sativa, right), and the progeny of their spontaneous hybrids resulted from gene flow (two in the middle). 
Editorial: Transgene containment by molecular means — is it possible and cost effective?

weedy/wild relative species, introgression of transgenes into the wild species will occur at a considerable frequency (Ellstrand and Hoffman, 1990; Dale, 1994; Lu et al., 2003).

Crop-to-crop gene flow will result in contamination of non-GM varieties, affecting the strategic deployment of transgenic and non-transgenic crop varieties in a given agricultural system. Significant contamination of nonGM crops with transgenic individuals poses difficulties in international trade because of legal restrictions on imports of transgenic products by many countries. Cropto-crop gene flow can also cause stacking of transgenes in the hybrids that can potentially become volunteer weeds if the transgenes impart multiple resistance, e.g. to herbicides (Hall et al., 2000), pests, and diseases. Crop-to-wild gene flow will lead to transgene escape into weedy populations or wild relative species, which might pose serious weed problems and other ecological risks if the transgenes persist and establish in the weedy/ wild populations through sexual reproduction and/or vegetative propagation (Ellstrand, 2001; Dale et al., 2002; Snow, 2002). This becomes more severe when the escaped genes can significantly enhance ecological fitness of the weedy/wild species.

\section{MEASURES TO PREVENT TRANSGENE ESCAPE}

To prevent or minimize pollen-mediated gene flow between GM crops and their weedy/wild relative species, a number of measures have been proposed and some are already being practiced. These include (i) physical isolation of the transgenic crop and (ii) molecular approaches for gene containment.

The physical approach is practiced by having an isolation zone of significant distance or planting a barrier strip (to serve as a pollen trap) around the GM crop. It was also recommended to reduce transgene escape by applying a post harvest herbicide or mechanical cultivation of the isolation areas around the field (Arriola, 1997). However, such efforts of gene containment in GM crops are ineffective and impracticable if the crop and wild species are distributed sympatrically (Snow, 2002). It has been found that pollen can be dispersed over distances of more than $1 \mathrm{~km}$ (Klinger et al., 1992; Rieger et al., 2002), which adds the complexity to the practice of isolation. It will become even more difficult when more GM crops are released and planted over increasingly vast areas in the future, but managed in small plots by different farming households, as is the case in many developing countries.
With the availability of current molecular technologies, scientists are attempting to explore opportunities for gene containment in transgenic crops using molecular approaches. In fact, various molecular technologies are currently being developed for transgene containment and expression under a certain condition (Daniell et al., 1998; 2001a, b; Gressel, 1999; Eastham and Sweet, 2002; Daniell, 2002). The fundamental principle of these technologies is to alter gene flow by interfering with pollination and fertilization, (using maternal inheritance and male sterility), terminating transgenic fruit/seed development (seed sterility), or compromising the fitness of weeds that have acquired positive survival traits from crop genes through introgression (transgenic mitigation). These strategies certainly provided new thoughts and dimensions for containment of transgenes in transgenic crops, but they also pose two questions: (i) Is transgene containment possible, even by application of molecular means? (ii) Is its cost effective to develop molecular biotechnologies for transgene containment when we still know little about the ecological impact of transgene escape into the environment?

Altering gene flow by interfering with pollination to confine genes of a transgenic crop from its nontransgenic counterparts or wild relatives/weedy species can be done by genetic engineering of chloroplasts (or other cytoplasmic organelles) to promote maternal inheritance of transgenes. This prevents pollen-mediated transgenes outflow because the chloroplast genomes are usually maternally inherited and pollen would not transmit the transgenes. However, this strategy does not take into consideration the fundamental biological fact that pollen-mediated gene flow is two-directional, as shown in Figure 1. This means that while transgenic plants disseminate their pollen, at the same time they also receive pollen from other plants including their wild relative species, resulting in hybridization. Hybrids with transgenic crops as the maternal parent and wild relatives as the paternal parent will carry transgenes. These hybrids and their backcrossed progeny with the wild parents could become potential weeds in agricultural systems. Reciprocal crop-to-wild gene flow and its resulted hybrids have been occasionally reported in different crop species (Boudry et al., 1993; Arriola, 1997). Such wild-to-crop gene flow can be expected to happen when a crop receives pollen from its close wild relative and weedy individuals. Therefore, chloroplast engineering does not solve the problem of gene flow, despite its several other advantages (Daniell, 2002). Similarly, when male-sterile transgenic plants receive pollen from and hybridize with their weedy types or close 
wild relatives, fertility might be restored in the hybrids, which will carry the transgenes. If the transgenes persist and get established in nature, the hybrids have the potential to eventually become weeds.

Transgene containment by the use of cleistogamy appears to be innovative for some crop species, but it is not practical for all crop species. Many crops such as maize, common buckwheat, cassava, and most cucurbits are allogamous, and it is extremely difficult to create cleistogamous plants for these crops. Even in the case of autogamous crops, the manipulation of cleistogamy may alter floral structures and natural flowering habit of some species. Such alteration might affect yield of those crops whose grains/seeds are the part harvested.

Another strategy to reduce the risks of transgenic traits spreading into relatives is by releasing transgenic lines with incompatible genomes. This is based on the fact that many cultivated crops have multiple genomes and for a particular crop, only one genome is in principle compatible for interspecific hybridization with its wild relatives. In other words, the extent of transgene exchange from an allopolyploid crop to its wild diploid relatives depends on the genome where the transgene is located. Gene introgression between different genomes with low homology tends to be low. Therefore, the risk of transgenes spreading into wild/weedy relatives can be significantly reduced in this system. Besides the fact that this approach is not likely to work for all crops, the basis of genome incompatibility for transgene containment has two flaws. First, incompatibility of genomes is not strict. Cytological studies showed a considerable amount of genetic recombination between homoeologous (incompatible) genomes, particularly when genetically controlled promoters for chromosome pairing are involved (Okamoto, 1957; Dvorak, 1972; Sears, 1983; Lu et al., 1991). Examples of intergenomic genetic recombination are extensively found in wheat chromosome engineering, where alien genes from homoeologous chromosomes are successfully used for breeding (Sears, 1983; Kimber, 1983; Knott, 1989). It was reported that oilseed rape could also transmit genes to its wild relatives even when those genes are carried on homoeologous chromosomes (Snow, 2002). Second, some hybrids between crop species and their wild relatives are perennial. Therefore, even if no immediate introgression occurs between genomes of a transgenic crop and its wild relatives, transgenes already subsist in the hybrids that can propagate vegetatively without producing seeds. If spontaneous chromosome doubling takes place, the sterile hybrids will become fertile polyploid hybrids and establish themselves in natural habitats through sexual reproduction.

The mechanism of seed-sterile technology (or terminator technology) for gene containment is sophisticated. The technology depends on a cleverly controlled sequence of interactions among the spliced-in genes with their on/off switches, to genetically switch off a plant's ability to germinate under a certain condition. This seed-suicide technology was originally designed for the protection of breeder's right, and has generated tremendous debate around the world. Its role in transgene containment still needs to be scientifically justified, quite apart from socio-economic concerns. To date, a number of gene-interaction systems have been developed, and the well-known terminator technology is triggered by a specific exogenous stimulus, such as the antibiotic tetracycline, for a three-gene (encoding Cre, RIP, and Tet) interaction system (for details see Odell et al., 1994; Daniell, 2002). The worry is that the three genes must always remain tightly linked together. If during reproduction they do not segregate together, and the Tet repressor passes on to one plant while the Cre (site specific recombinase) and RIP (cytotoxic ribosome-inhibitor protein) segregate to another, all the seeds produced by plants with Cre and RIP would be sterile. The problem is that genetic recombination and segregation happen frequently in nature and are beyond human control. Once the terminator seeds are released into the environment, and the trait of seed sterility might be passed to other non-GM crops or weedy/wild relatives through outcrossing, probably making some of the seeds in the region sterile. Another worry is that if the late embryonic abundance promoter (that is responsible for destruction of seed tissue) is subject to silencing or the transgenes of interest are segregated from the terminator construct through recombination, the transgenes will spread to the weedy/ wild relatives, posing ecological consequences.

Transgenic mitigation (TM) has received growing attention as an approach for containing transgene spread by compromising the fitness of weeds that have positive survival traits (e.g., non-dormancy, uniform ripening, and anti-shattering of seeds) from crop genes through introgression (for details see Gressel, 1999; Daniell, 2002). The success of TM is based on the premises that tandem constructs including the TM traits and traits of interests act as tightly linked genes and their segregation is extremely rare. However, the concerns with TM as a method to contain transgenes are as follows. First, this technology does not address the problems of transgene escape from a GM crop to non-GM crop varieties and its weedy/wild species through gene flow, even though it is 
Editorial: Transgene containment by molecular means — is it possible and cost effective?

possible to design such genes for weed/wild deterioration or fitness-reduction and insert them next to the target transgenes. The destiny and long-term consequences of the mitigation genes in crop and weedy/wild populations are as yet unpredictable. Second, organization of tandem constructs with tightly linked genes will require considerable efforts of multigene engineering. Envisaging future attempts to transfer multiple genes with different functions into one crop variety in later generations of transgenic biotechnology make the constructs particularly difficult. Finally, the so-called traits of compromised fitness, such as seed dormancy, seed shattering, and protracted seed ripening, are usually controlled by dominant alleles. It is hard to predict the genetic expression of the mitigated genes when they escape to and persist in the wild populations. In other words, the long-term ecological consequences of these transgenes in environment are still unpredictable.

\section{ISSUES, CHALLENGES AND STRATEGIES}

Given the fact that gene flow is inevitable under natural conditions, containment of transgenes is nearly impossible and not practical, particularly as more transgenic crop varieties are produced and released to environment in the near future. Our present knowledge on the ecological impact of transgene escape through gene flow is still extremely limited.

What then will be our strategy for environmental biosafety studies? Should we allocate our investment to developing more sophisticated biotechnology tools for transgene containment, or to assessing more extensively the ecological impact of transgenes that will spread to (or are already in) the environment? I believe that the latter choice would be wiser and more profitable for the longterm sustainable development of GM crops, as well as for a more scientific understanding of the dynamics of transgenes in the environment. The case-by-case principle of biosafety assessment indicates clearly that not all crops have high risks to spread their genes in a particular geographic location (e.g., soybean in the USA and rice in the UK), and that not all genes are harmful to the environment. The environmental risks of such genes as high protein and vitamin content, dwarf, and delayed ripening that do not have significant selective advantages in nature in terms of evolution would be limited. On the other hand, genes that encode insect-specific toxins (like $B t$ and $C p T I$ ), or resistance to an herbicide or abiotic stresses might pose serious environmental problems. In addition, indiscriminate use of biotechnology for containment of transgenes without prior understanding of their specific ecological and environmental impacts will only increase the cost of producing GM crops. The high costs will ultimately be borne by farmers, and passed on to consumers.

The commercial release of transgenic crops should be preceded by thorough research on their environmental impacts. Extensive assessment of the ecological impacts of transgene escape to environment is desperately needed. This includes studies of transgene persistence to and establishment in weedy and wild populations, distribution and dynamics of the populations that acquire transgenes, and genetic expression of transgenes in weedy and wild individuals under natural conditions. This knowledge will assist in promoting further development of the transgenic biotechnology, and safe deployment and use of its products.

\section{ACKNOWLEDGEMENT}

The support of NSFC for Distinguished Young Scholars (Grant No. 30125029) and Science and Technology Commission of Shanghai (Grant No. 02JC14022) is kindly acknowledged. Dr. S.P. Kam of the International Rice Research Institute provided constructive suggestions on this manuscript.

Received September 4, 2002; accepted November 14, 2002.

\section{REFERENCES}

Arriola PE (1997) Risks of escape and spread of engineered genes from transgenic crops to wild relatives. AgBiotech News Inform. 9: 157-160

Arriola PE, Ellstrand NC (1996) Crop-to-weed gene flow in the genus Sorghum (Poaceae): Spontaneous interspecific hybridization between johnsongrass, Sorghum halepense, and crop sorghum, S. bicolor. Am. J. Bot. 83: 1153-1159

Boudry P, Mörchen M, Saumitou-Laprade P, Vernet P, Van Dijk H (1993) The origin and evolution of weed beets: consequences for the breeding and release of herbicideresistant transgenic sugar beets. Theor. Appl. Genet. 87: $471-478$

Crawley MJ, Brown SL, Hails RS, Kohn DD, Rees M (2001) Biotechnology - Transgenic crops in natural habitats. Nature 409: 682-683

Dale PJ (1994) The impact of hybrids between genetically modified crop plants and their related species: general considerations. Mol. Ecol. 3: 31-36 
Dale PJ, Clarke B, Fontes EMG (2002) Potential for the environmental impact of transgenic crops. Nat. Biotechnol. 20: $567-574$

Daniell H (2002) Molecular strategies for gene containment in transgenic crops. Nat. Biotechnol. 20: 581-586

Daniell H, Khan MS, Allison L (2001a) Milestones in chloroplast genetic engineering: an environmentally friendly era in biotechnology. Trends Plant Sci. 7: 84-91

Daniell H, Muthukumar B, Lee SB (2001b) Engineering the chloroplast genome without antibiotic selection. Curr. Genet. 39: $109-116$

Daniell H, Datta R, Varma S, Gray S, Lee SB (1998) Containment of herbicide resistance through genetic engineering of the chloroplast genome. Nat. Biotechnol. 16: 345-348

Dvorak J (1972) Genetic variability in Aegilops speltoides affecting homoelogous pairing in wheat. Can. J. Genet. Cytol. 14: $371-380$

Eastham K, Sweet J (2002) Genetically modified organisms (GMOs): the significance of gene flow through pollen transfer. Environmental Issue Report 28 (European Evironmental Agency, Copenhagen, Denmark

Ellstrand NC (2001) When transgenes wander, should we worry? Plant Physiol. 125: 1543-1545

Ellstrand NC, Hoffman CA (1990) Hybridization as an avenue of escape for engineered genes. Bioscience 40: 438-442

Ellstrand NC, Prentice HC, Hancock JF (1999) Gene flow and introgression from domesticated plants into their wild relatives. Annu. Rev. Ecol. Syst. 30: 539-563

Gressel J (1999) Tandem constructs: preventing the rise of superweeds. Trends Biotechnol. 17: 361-366

Hall L, Topinka K, Huffman J, Vavis L (2000) Pollen flow between herbicide-resistant Brassica napus is the cause of multiply-resistant B. napus volunteers. Weed Sci. 48 : 688-694

James C (2001) Global review of commercialized transgenic crops: 2001. ISAAA Briefs No. 24: Preview. Ithaca, NY. http://www.isaaa.org/publications

Jenczewski E, Ronfort J, Chèvre AM (2002) Crop-to-wild gene flow, introgression and possible fitness effects of transgenes. Environ. Biosafety Res. 2: 9-24

Kimber G (1983) Genomic analysis in the genus Triticum. In Sakamoto S, ed, Proc. 6th Intern. Wheat Genet. Symp., Kyoto, Japan, Kyoto University, pp 23-28

Klinger T, Arriola PE, Ellstrand NC (1992) Crop-
Weed hybridization in Radish (Raphanus sativus): effects of distance and population size. Am. J. Bot. 79: 1431-1435

Knott DR (1989) The effect of transfer of alien genes for rust resistance on the agronomic and quality characteristics of wheat. Euphytica 44: 65-72

Langevin SA, Clay K, Grace JB (1990) The incidence and effects of hybridization between cultivated rice and its related weed red rice (Oryza sativa L). Evolution 44: 1000-1008

Lu BR, Salomon B, Bothmer R von (1991) Meiotic studies of the progenies from intergeneric crosses Elymus $\times$ Hordeum and Elymus $\times$ Secale. Genome 33: 425-432

Lu BR, Naredo MBE, Juliano AB, Jackson MT (2000) Preliminary studies on taxonomy and biosystematics of the AA genome of Oryza species (Poaceae). In Jacobs SWL, Everett J, eds, Grasses: Systematics and Evolution, pp 51-58

Lu BR, Song ZP, Chen JK (2003) Can transgenic rice cause ecological risks through transgene escape? Prog. Nat. Sci. 13: $17-24$

Messeguer J, Fogher C, Guiderdoni E, Marfa V, Catala MM, Baldi G, Mele E (2001) Filed assessment of gene flow from transgenic to cultivated rices (Oryza sativa L.) using a herbicide resistance genes as tracer marker. Theor. Appl. Genet. 103: 1151-1159

Odell JT, Hoopes JL, Vermerris W (1994) Seed-specific gene activation mediated by the Cre/lox site-specific recombination system. Plant Physiol. 106: 447-458

Okamoto M (1957) Asynaptic effect of chromosome V. Wheat Info. Serv. 5: 6

Prakash CS (2001) The genetically modified crop debate in the context of agricultural evolution. Plant Physiol. 126: 8-5

Rieger MA, Potter TD, Preston C, Powles SB (2001) Hybridisation between Brassica napus L. and Raphanus raphanistrum L. under agronomic field conditions. Theor. Appl. Genet. 103: 555-560

Rieger MA, Lamond M, Preston C, Powles SB, Roush RT (2002) Pollen-mediated movement of herbicide resistance between commercial canola fields. Science 296: 2386-2388

Sears ER (1983) The transfer to wheat of interstitial segments of alien chromosomes. In Sakamoto S, ed, Proc. 6th Intern. Wheat Genet. Symp., Kyoto, Japan, Kyoto University, pp 5-12

Snow A (2002) Transgenic crops - why gene flow matters. Nat. Biotechnol. 20: 542

Wolfenbarger LL, Phifer PR (2000) The ecological risks and benefits of genetically engineered plants. Science 290: 2088-2093 